\title{
OPEN A repeated cross-sectional analysis assessing mental health conditions of adults as per student status during key periods of the COVID-19 epidemic in France
}

\author{
Melissa Macalli ${ }^{1 凶}$, Nathalie Texier², Stéphane Schück ${ }^{2}$, Sylvana M. Côté ${ }^{1,3}$ \& \\ Christophe Tzourio ${ }^{1 \bowtie}$
}

Previous studies have shown the negative impact of the COVID-19 epidemic on students' mental health. It is, however, uncertain whether students are really at higher risk of mental health disturbances than non-students and if they are differentially impacted by lockdown periods over time. The objective of our study was to compare the frequency of depressive symptoms, anxiety, and suicidal thoughts in students and non-students enrolled in the same study in France and during the same key periods of the COVID-19 epidemic. Using a repeated cross-sectional design, we collected data from a sample of $\mathbf{3 7 8 3}$ participants in the CONFINS study during three recruitment waves between March 2020 and January 2021. Multivariate logistic regression models, adjusted for potential confounding factors, showed that students were more likely to have high scores of depressive symptoms and anxiety more frequently than non-students. These differences were particularly strong during the first (depressive symptoms: adjusted odds ratio aOR 1.59, 95\% Cl 1.22-2.08; anxiety: aOR 1.63, 95\% Cl 1.22-2.18) and second lockdowns (depressive symptoms: aOR 1.80, 95\% Cl 1.04-3.12; anxiety: aOR $2.25,95 \% \mathrm{Cl} 1.24-4.10$ ). These findings suggest that the restrictive measures-lockdown and curfew-have an alarmingly stronger negative impact on students than on non-students and underline the frailty of students' mental health and the need to pay greater attention to this population in this epidemic-related context.

Even before the COVID-19 pandemic, it was known that college students have a high prevalence of mental health problems $s^{1,2}$. In France, as in most high-income countries, suicide is the second-leading cause of death among individuals aged 15 to 25 years, and a national student cohort has reported high rates of depression, anxiety, and suicidal thoughts ${ }^{3}$.

In the first stages of the epidemic, France was one of the most affected countries in the world in number of cases and deaths $s^{4,5}$, leading to an early lockdown in March 2020, followed by another lockdown period in October 2020. The negative impact of the COVID-19 epidemic and lockdown on mental health has been reported in some population-based studies ${ }^{6-8}$, some including students ${ }^{9,10}$. A recent meta-analysis including 27 studies constituting 90,879 college students in 15 countries reported $39.4 \%$ having anxiety and $31.2 \%$ having depression during the COVID-19 epidemic ${ }^{11,12}$.

To our knowledge, most of these studies were conducted in the initial months of the pandemic and, to date, none of them has presented some prevalence of mental health problems among students during the second lockdown in France. It is, however, uncertain whether students are indeed at higher risk of mental health disturbances than non-students or if they are differentially impacted by lockdown periods over time. Our objective was to compare the frequency of depressive symptoms, anxiety, and suicidal thoughts in students and non-students enrolled in the same study, in key periods of the COVID-19 epidemic from March 2020 to January 2021 in France.

\footnotetext{
${ }^{1}$ Inserm, Bordeaux Population Health Research Center, UMR 1219, University of Bordeaux, 146 Rue Léo Saignat, 33076 Bordeaux Cedex, France. ${ }^{2}$ Kappa Santé, 4 Rue de Cléry, 75002 Paris, France. ${ }^{3}$ School of Public Health, University of Montreal, Montreal, OC H3T 1J4, Canada. ${ }^{\boxplus}$ email: melissa.macalli@u-bordeaux.fr; christophe.tzourio@u-bordeaux.fr
} 


\section{Methods}

Design, study population, and data source. Our study sample comprised participants in the ongoing web-based CONFINS cohort (www.confins.org), a prospective population-based study launched in March 2020 to address the psychological impact of COVID-19. Participants were recruited via advertisement in traditional and social media. To be eligible, subjects had to be aged 18 or older (without any upper age bar) and to have been confined in France. All participants provided an on-line informed consent. Using a repeated cross-sectional design, data collection occurred during three recruitment periods corresponding to key periods of the COVID19 epidemic in France: (1) period 1: the first national lockdown (17th March-11th May, 2020); (2) period 2: no lockdown restrictions (12th May-27th October, 2020); and (3) period 3: the second national lockdown and curfew (28th October, 2020-25th January, 2021).

Measures. Depressive symptoms: participants completed the French version of the 9-item Patient Health Questionnaire (PHQ-9), which is a reliable, valid measure of depression severity ${ }^{13,14}$. We used a validated cut-off of 10 to define the presence of depressive symptoms ${ }^{15}$.

Anxiety symptoms: participants completed the French version of the Generalized Anxiety Disorder-7 scale (GAD-7), a validated brief measure for assessing generalized anxiety symptoms ${ }^{16,17}$. We used a validated cut-off score of 10 to define the presence of anxiety symptoms ${ }^{16}$.

Suicidal thoughts: the questionnaire included a single-item question about suicidal thoughts during the last 7 days, as follows: "During the past 7 days, how often have you thought of attempting suicide (had suicidal ideation)?" Participants selected one of three possible responses: (1) no suicidal thoughts, (2) occasional suicidal thoughts, and (3) frequent suicidal thoughts. Occasional or frequent suicidal thoughts were considered together in this analysis.

Covariates: the following self-reported covariates were considered in the analyses: age, gender (male, female, other), marital status (single, married, or in a couple), education level (university studies or not), and psychiatric disease history (yes/no).

Statistical analyses. We first described the overall study sample and grouped participants according to their student status and inclusion period. The continuous variable "age" is expressed as the mean \pm standard error. Categorical variables are described as the count and proportion (\%). The Kruskal-Wallis test was used to compare distributions of age in the groups (students or not). Proportions were compared using the chi-square test. To compare the frequency of mental health outcomes between students and non-students in each period, we used logistic regression models. The results are expressed as adjusted odds ratios (aORs) with 95\% confidence intervals (CIs). Model convergences were checked. The assumption of linearity of the logit was tested for the continuous variable "age" in each model. The fully adjusted analyses took into account all selected covariates. In each model, to account for missing information on covariates, namely psychiatric disease history, we used the multiple imputation-by-chained equation method. Briefly, we performed 10 imputations and averaged the variable estimates to produce a mean estimate. Finally, we verified that the relative efficiency of the imputation for each variable was greater than $95 \%$.

All analyses were performed using SAS version 9.4. Two-sided P values $<0.05$ were considered statistically significant.

Ethics approval. The study follows the principles of the Declaration of Helsinki, and the collection, storage, and analysis of the data comply with the General Data Protection Regulation (EU GDPR). The study was approved by the French Committee for the Protection of Individuals (Comite de Protection des PersonnesCPP IDF X, nr. 46-2020) and by the National Commission on Informatics and Liberty (Commission Nationale de l'Informatique et des Libertes) CNIL, nr. MLD/MFI/AR205600).

Consent to participate. Students were informed of the nature and purpose of the study and provided online consent.

\section{Results}

Among the 3783 participants included, $66.6 \%(\mathrm{n}=2518 ; 59.1 \%$ students) were recruited during period 1 (the first lockdown), $21.4 \%$ ( $\mathrm{n}=811 ; 63.6 \%$ students) during period 2 (no lockdown), and $12.0 \%$ ( $\mathrm{n}=454 ; 73.4 \%$ students) during period 3 (the second lockdown and curfew). Table 1 shows the characteristics of the study sample overall and according to the student status and the inclusion period. The mean age of the entire sample was 29.2 years $(\mathrm{SD} \pm 11.7)$ : 38.4 years $(\mathrm{SD} \pm 13.9)$ for the non-students and 23.4 years $(\mathrm{SD} \pm 3.9)$ for the students. About threequarters were female $(n=2971 ; 78.6 \%)$ and about one participant in five reported psychiatric disease history.

The majority of the non-students $(n=1185 ; 80.6 \%)$ declared a university education level. This group was more likely to be married or in a couple than were students $(69.2 \%$ vs. $47.9 \%)$. Important concerns about financial situation were more frequent among students than among non-students ( $21.4 \%$ vs. $1.7 \%)$. The patterns of sociodemographic characteristics of each group were stable, whatever the inclusion period.

In the overall sample, students had higher rates of mental health symptoms than non-students, including depressive symptoms (36.6\% vs. $20.1 \%$ ), anxiety (27.5\% vs. $16.9 \%)$, and suicidal thoughts ( $12.7 \%$ vs. $7.9 \%)$. Moreover, we observed a dramatic differential pattern between students and non-students according to the period (Fig. 1). Specifically, among students, there was a higher frequency of depressive symptoms and anxiety during the first and second lockdowns compared with the no-lockdown period. Among non-students, the rates of mental health conditions were relatively stable over time. When comparing both groups, the frequency of 


\begin{tabular}{|c|c|c|c|c|c|c|c|c|c|c|c|c|}
\hline & \multicolumn{3}{|c|}{ All sample $(n=3783)$} & \multicolumn{3}{|c|}{ First lockdown $(n=2518 ; 66.6 \%)$} & \multicolumn{3}{|c|}{ No-lockdown period $(\mathrm{n}=811 ; 21.4 \%)$} & \multicolumn{3}{|c|}{ Second lockdown $(n=454 ; 12.0 \%)$} \\
\hline & Total & $\begin{array}{l}\begin{array}{l}\text { Non- } \\
\text { students } \\
(\mathrm{n}=1470\end{array} \\
38.9 \%)\end{array}$ & $\begin{array}{l}\text { Students } \\
(\mathrm{n}=2313 \\
61.1 \%)\end{array}$ & Total & $\begin{array}{l}\begin{array}{l}\text { Non- } \\
\text { students } \\
(n=1031 ;\end{array} \\
41.0 \%)\end{array}$ & $\begin{array}{l}\text { Students } \\
(\mathrm{n}=1487 \\
59.1 \%)\end{array}$ & Total & \begin{tabular}{|l|}
$\begin{array}{l}\text { Non- } \\
\text { students }\end{array}$ \\
$(\mathrm{n}=295 ;$ \\
$36.4 \%)$
\end{tabular} & $\begin{array}{l}\text { Students } \\
(\mathrm{n}=516 ; \\
63.6 \%)\end{array}$ & Total & \begin{tabular}{|l}
$\begin{array}{l}\text { Non- } \\
\text { students }\end{array}$ \\
(n=144; \\
$26.6 \%)$
\end{tabular} & $\begin{array}{l}\text { Students } \\
(\mathrm{n}=310 \\
73.4 \%)\end{array}$ \\
\hline $\begin{array}{l}\text { Age mean } \\
\text { (SD) }\end{array}$ & $29.2(11.7)$ & $38.4(13.9)$ & $23.4(3.9)$ & $30.1(12.6)$ & $40.0(14.2)$ & $23.3(3.9)$ & $27.8(9.6)$ & $34.6(12.1)$ & $23.9(3.8)$ & $26.9(9.8)$ & $35.2(12.9)$ & $23.1(3.9)$ \\
\hline \multicolumn{13}{|l|}{ Gender } \\
\hline Men & $20.8(785)$ & $23.4(344)$ & $19.1(441)$ & $21.7(547)$ & $24.0(247)$ & $20.2(300)$ & $19.1(155)$ & $20.7(61)$ & $18.2(94)$ & $18.3(83)$ & $25.0(36)$ & $15.2(47)$ \\
\hline Women & $78.6(2971)$ & $76.1(1119)$ & $80.1(1853)$ & $77.6(1954)$ & $75.6(779)$ & $79.0(1175)$ & $80.5(653)$ & $79.0(233)$ & $81.4(420)$ & $80.2(364)$ & $74.3(107)$ & $82.9(257)$ \\
\hline Other & $0.7(27)$ & $0.5(7)$ & $0.9(20)$ & $0.7(17)$ & $0.5(5)$ & $0.8(12)$ & $0.4(3)$ & $0.3(1)$ & $0.4(2)$ & $1.6(7)$ & $0.7(1)$ & $1.9(6)$ \\
\hline \multicolumn{13}{|c|}{ Marital status } \\
\hline $\begin{array}{l}\text { Married or } \\
\text { in a couple }\end{array}$ & $56.2(2125)$ & $69.2(1017)$ & $47.9(1108)$ & $56.5(1422)$ & $69.3(714)$ & $47.6(708)$ & $57.3(465)$ & $68.8(203)$ & $50.8(262)$ & $52.4(238)$ & $30.6(44)$ & $55.5(172)$ \\
\hline Single & $43.8(1658)$ & $30.8(453)$ & $52.1(1205)$ & $43.5(1096)$ & $30.8(317)$ & $52.4(779)$ & $42.7(346)$ & $31.2(92)$ & $49.2(254)$ & $47.6(216)$ & $69.4(100)$ & $44.5(138)$ \\
\hline \multicolumn{13}{|c|}{ University studies } \\
\hline & $92.5(3498)$ & $80.6(1185)$ & $\begin{array}{l}100.0 \\
(2313)\end{array}$ & $90.7(2283)$ & $77.2(796)$ & $\begin{array}{l}100.0 \\
(1487)\end{array}$ & $94.5(766)$ & $84.8(250)$ & 100.0 & $98.9(449)$ & 96.5 (139) & $100.0(310)$ \\
\hline \multicolumn{13}{|c|}{ Concerns about financial situation } \\
\hline $\begin{array}{l}\text { Important } \\
\text { to very } \\
\text { important }\end{array}$ & $19.6(725)$ & $16.7(242)$ & $21.4(483)$ & $20.3(502)$ & $17.5(178)$ & $22.3(324)$ & $16.9(134)$ & $14.9(43)$ & $18.1(91)$ & $19.9(89)$ & $14.9(21)$ & $22.2(68)$ \\
\hline Few or no & $43.8(1658)$ & $83.3(1204)$ & $78.6(1778)$ & $79.7(1967)$ & $82.5(838)$ & $77.7(1129)$ & $83.1(657)$ & $85.1(246)$ & $81.9(411)$ & $80.1(358)$ & $85.1(120)$ & $77.8(238)$ \\
\hline \multicolumn{13}{|c|}{ Psychiatric disease history $($ missing $=657)$} \\
\hline & $21.0(656)$ & $21.3(247)$ & $20.8(409)$ & $23.1(443)$ & $23.7(176)$ & $22.7(267)$ & $18.4(134)$ & $20.1(54)$ & $17.4(80)$ & $20.4(79)$ & $13.0(17)$ & $24.2(62)$ \\
\hline \multicolumn{13}{|c|}{ Depressive symptoms } \\
\hline & $30.2(1141)$ & $20.1(295)$ & $36.6(846)$ & $29.1(733)$ & $18.7(193)$ & $36.3(540)$ & $25.8(203)$ & $21.4(63)$ & $27.1(140)$ & $45.2(205)$ & $27.1(39)$ & $53.6(166)$ \\
\hline \multicolumn{13}{|l|}{ Anxiety } \\
\hline & $23.4(884)$ & $16.9(249)$ & $27.5(635)$ & $22.1(557)$ & $15.9(164)$ & $26.4(393)$ & $20.0(59)$ & $21.1(109)$ & $20.1(109)$ & $35.0(159)$ & $18.1(26)$ & $42.9(133)$ \\
\hline \multicolumn{13}{|c|}{ Suicidal thoughts $($ missing $=740$ ) } \\
\hline & $10.9(331)$ & $7.9(89)$ & $12.7(242)$ & $10.1(195)$ & $7.3(54)$ & $11.9(142)$ & $10.5(76)$ & $8.3(22)$ & $11.8(54)$ & $15.5(60)$ & $11.1(14)$ & $17.6(46)$ \\
\hline
\end{tabular}

Table 1. Characteristics of the study sample overall and according to the student status and the inclusion period, CONFINS study (2020-2021). All data presented as $\%(N)$ unless otherwise noted (SD: Standard deviation). Two-sided $P$ values $<0.05$ were considered statistically significant based on Kruskal-Wallis test for continuous variable and chi-square test for categorical variables comparing students and non-students (results in bold).

\section{STUDENTS}

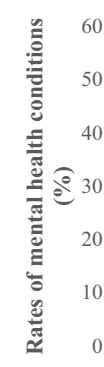

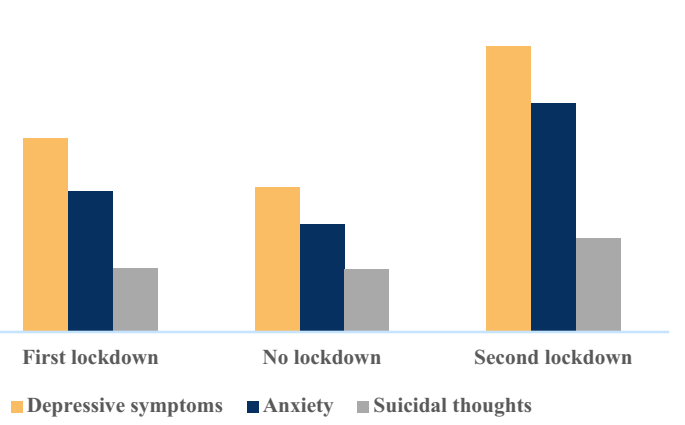

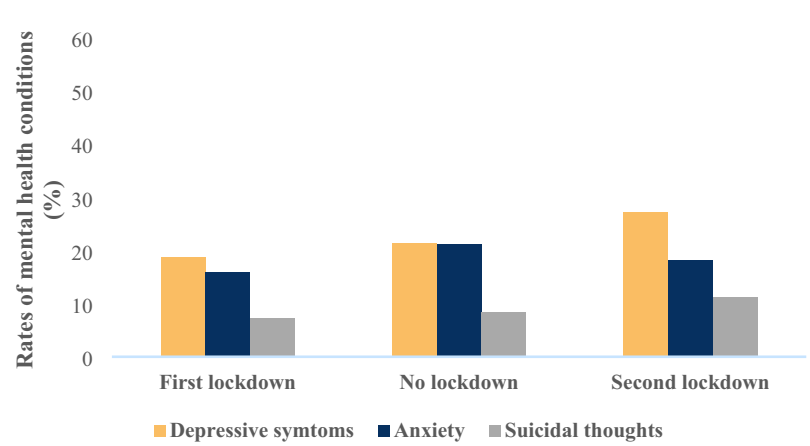

Figure 1. Rates of depressive and anxious symptoms as well as suicidal thoughts (\%) among students and nonstudents according to key periods of the COVID-19 epidemic in France, CONFINS study (2020-2021).

depressive symptoms during the first lockdown was nearly twice as high in students as in non-students (36.3\% vs. $18.7 \%$; $\mathrm{P}<0.0001)$. In period 2 with no lockdown restrictions, the difference was attenuated $(27.1 \%$ in students vs. $21.4 \% ; \mathrm{P}=0.0677$ ) and non-significantly different. However, during the second lockdown, more than one-half of the students had depressive symptoms, compared with about one-quarter of the non-students $(53.6 \%$ vs. $27.1 \%$; $\mathrm{P}<0.0001)$.

Multivariate analyses confirmed significant variations in the rates of mental health conditions over time in the student population, but not in the non-student population (Table 2). Adjusting for age, gender, psychiatric 


\begin{tabular}{|c|c|c|c|c|c|c|}
\hline & \multicolumn{2}{|c|}{ First lockdown } & \multicolumn{2}{|c|}{ No-lockdown period } & \multicolumn{2}{|c|}{ Second lockdown } \\
\hline & OR & $95 \% \mathrm{CI}$ & OR & $95 \% \mathrm{CI}$ & OR & $95 \% \mathrm{CI}$ \\
\hline \multicolumn{7}{|l|}{ Model 1} \\
\hline Depressive symptoms & 1.44 & [1.10-1.89] & 1.24 & [0.81-1.89] & 2.13 & {$[1.24-3.66]$} \\
\hline Anxiety & 1.52 & [1.14-2.05] & 0.82 & [0.52-1.29] & 2.65 & [1.46-4.82] \\
\hline \begin{tabular}{|l|} 
Suicidal thoughts \\
\end{tabular} & 1.59 & {$[0.98-2.56]$} & 1.35 & {$[0.72-2.55]$} & 1.24 & {$[0.56-2.79]$} \\
\hline \multicolumn{7}{|l|}{\begin{tabular}{|l|} 
Model 2 \\
\end{tabular}} \\
\hline Depressive symptoms & 1.59 & {$[1.22-2.08]$} & 1.17 & {$[0.76-1.80]$} & 1.80 & [1.04-3.12] \\
\hline Anxiety & 1.63 & {$[1.22-2.18]$} & 0.94 & {$[0.59-1.48]$} & 2.25 & [1.24-4.10] \\
\hline \begin{tabular}{|l|} 
Suicidal thoughts \\
\end{tabular} & 1.21 & {$[0.91-1.60]$} & 0.82 & {$[0.42-1.61]$} & 0.99 & {$[0.53-1.85]$} \\
\hline
\end{tabular}

Table 2. Association between college student status and depressive symptoms $(n=3783)$, anxiety $(n=3783)$, suicidal thoughts $(n=3043)$ according to key periods of the COVID-19 epidemic in France, CONFINS study (2020-2021). Model 1 adjusted for age and gender; Model 2 adjusted for age, gender, psychiatric disease history, education level, marital status and after multiple imputation on psychiatric disease history. OR odds ratio, $C I$ confidence interval.

disease history, education level, and marital status, students had an approximately $60 \%$ increase in risk of depressive symptoms (aOR 1.59, 95\% CI 1.22-2.08) and anxiety (aOR 1.63, 95\% CI 1.22-2.18) compared with nonstudents during the first lockdown. During the second lockdown, the point estimates were even higher for both depressive symptoms (aOR 1.80, 95\% CI 1.04-3.12) and anxiety (aOR 2.25, 95\% CI 1.24-4.10). However, in the no-lockdown period, there was no difference between the two groups. There was no statistically significant difference between groups regarding suicidal thoughts at any period.

\section{Discussion}

In this study of 3783 participants, we found that students were more likely than non-students to have high scores for depressive symptoms and anxiety during the COVID-19 pandemic. This pattern was particularly strong during lockdown periods, suggesting that students are a more fragile group under these conditions. While the period with no lockdown restrictions was accompanied by a clear improvement in mental health outcomes in students, the second lockdown seemed to have an even stronger effect on these mental outcomes in students.

In the early stages of the epidemic, previous studies among students reported similar high prevalences of depressive and anxiety symptoms in other countries ${ }^{18-20}$ and in France ${ }^{12,21,22}$. Our findings could be explained by the lack of support, social isolation ${ }^{23,24}$, and well-known vulnerability of students to mental health problems ${ }^{1}$ that were likely exacerbated by the COVID-19 pandemic and lockdown restrictions. Since the beginning of the epidemic, students have had to modify their living and working habits and adapt to remote pedagogical practices. Most universities have been closed, and the loss of jobs or concerns about health may have contributed to the stress and declining mental health of student ${ }^{25}$. Moreover, the duration of the epidemic and the restrictions may also have led to a feeling of weariness and aggravated initial situations of vulnerability linked to the students' financial situations or social isolation.

This study has some important strengths, including the large sample of participants which allowed a comparison between students and non-students in different key periods of the COVID-19 pandemic. Students and non-students were recruited using the same strategy and differed mainly in mean age and marital status. Depressive and anxiety symptoms were measured using validated scales that have well-known appropriate psychometric properties. Despite these strengths, some limitations should be considered. First, our study design was cross-sectional. Therefore, these findings do not reflect the evolution of mental conditions in our population but the differences between samples of individuals recruited at different times during the epidemic. Second, the participants were volunteers, which may have introduced a self-selection bias. However, as mentioned above, recruitment strategies were maintained during the entire duration of the study and were based on the same messages for both students and non-students. Selection bias, if any, should have affected both groups similarly during the various recruitment phases. Third, because of the potential self-selection and the particularities of our sample, it is not possible to generalize our conclusions to all students and non-students in France or elsewhere. Nevertheless, we believe that the differences we observed between students and non-students may be similar in other settings. Fourth, the self-reported questionnaires could lead to information and recall bias, particularly if participants under-reported their frequency of mental health conditions due to concerns about social desirability. However, such under-reporting is likely to be reduced by the use of an online questionnaire and it is unlikely that it explains the large differences observed between students and non-students. Fifth, although we have included some major covariates in our multivariate models, unmeasured confounding factors could remain and partly explain the association between student status and mental health conditions.

In conclusion, our findings provide new insights into the mental health of university students during the COVID-19 epidemic. These results suggesting that the restrictive measures of lockdown and curfew have an alarmingly stronger negative impact on students than on non-students, underline the frailty of students' mental health, and show that greater attention should be given to this population. Future studies should implement appropriate interventions to reduce this impact and promote the mental health of students, for example by improving posttraumatic growth or stress management. Given that the COVID-19 epidemic and some 
restrictions are set to continue for some time and that long-term consequences to mental health are likely to occur, it is crucial that universities and public health systems consider long-term strategies in terms of screening and help to mitigate mental health disorders in students during the pandemic.

\section{Data availability}

The datasets used and/or analyzed during the current study are available from the corresponding author on reasonable request.

Received: 26 April 2021; Accepted: 5 October 2021

Published online: 09 November 2021

\section{References}

1. Auerbach, R. P. et al. WHO World mental health surveys international college student project: Prevalence and distribution of mental disorders. J. Abnorm. Psychol. 127, 623-638 (2018).

2. Bruffaerts, R. et al. Lifetime and 12 -month treatment for mental disorders and suicidal thoughts and behaviors among first year college students. Int. J. Methods. Psychiatr. Res. 28, e1764 (2019).

3. Macalli, M., Côté, S. \& Tzourio, C. Perceived parental support in childhood and adolescence as a tool for mental health screening in students: A longitudinal study in the i-Share cohort. J. Affect. Disord. 266, 512-519 (2020)

4. WHO. WHO Coronavirus Disease (COVID-19) Dashboard Who Coronavirus Disease (COVID-19) (2020). https://covid19.who. int/table?tableChartType=heat. Accessed on September 18, 2021.

5. John Hopkins University. COVID-19 Dashboard by the Center for Systems Science and Engineering (CSSE) at Johns Hopkins University (JHU) (2021). https://coronavirus.jhu.edu/map.html. Accessed on September 18, 2021.

6. Czeisler, M. É. Mental Health, substance use, and suicidal ideation during the COVID-19 pandemic-United States, June 24-30, 2020. MMWR Morb. Mortal. Wkly. Rep. 69, 1049 (2020).

7. Mazza, C. et al. A nationwide survey of psychological distress among Italian people during the COVID-19 pandemic: Immediate psychological responses and associated factors. Int. J. Environ. Res. Public Health 17, E3165 (2020).

8. Simon, N. M., Saxe, G. N. \& Marmar, C. R. Mental health disorders related to COVID-19-related deaths. JAMA 324, 1493-1494 (2020).

9. Debowska, A., Horeczy, B., Boduszek, D. \& Dolinski, D. A repeated cross-sectional survey assessing university students' stress, depression, anxiety, and suicidality in the early stages of the COVID-19 pandemic in Poland. Psychol. Med. https://doi.org/10. 1017/S003329172000392X (2020).

10. Wang, C. et al. Immediate psychological responses and associated factors during the initial stage of the 2019 coronavirus disease (COVID-19) epidemic among the general population in China. Int. J. Environ. Res. Public Health 17(5), 1729 (2020).

11. Batra, K., Sharma, M., Batra, R., Singh, T. P. \& Schvaneveldt, N. Assessing the psychological impact of COVID-19 among college students: An evidence of 15 Countries. Healthcare (Basel) 9, 222 (2021).

12. Wathelet, M. et al. Factors associated with mental health disorders among university students in France confined during the COVID-19 pandemic. JAMA Netw. Open 3, e2025591 (2020).

13. Kroenke, K., Spitzer, R. L. \& Williams, J. B. W. The PHQ-9. J. Gen. Intern. Med. 16, 606-613 (2001).

14. Arthurs, E. et al. Are scores on English and French versions of the PHQ-9 comparable? An assessment of differential item functioning. PLoS ONE 7, e52028 (2012).

15. Manea, L., Gilbody, S. \& McMillan, D. Optimal cut-off score for diagnosing depression with the patient health questionnaire (PHQ-9): A meta-analysis. CMAJ 184, E191-E196 (2012).

16. Spitzer, R. L. et al. A brief measure for assessing generalized anxiety disorder: The GAD-7. Arch. Intern. Med. 166, 1092-1097 (2006).

17. Micoulaud-Franchi, J.-A. et al. Rapid detection of generalized anxiety disorder and major depression in epilepsy: Validation of the GAD-7 as a complementary tool to the NDDI-E in a French sample. Epilepsy Behav. 57, 211-216 (2016).

18. Sun, S., Goldberg, S. B., Lin, D., Qiao, S. \& Operario, D. Psychiatric symptoms, risk, and protective factors among university students in quarantine during the COVID-19 pandemic in China. Glob. Health 17, 15 (2021).

19. Yu, Y. et al. Factors influencing depression and mental distress related to COVID-19 among university students in China: Online cross-sectional mediation study. JMIR Mental Health 8, e22705 (2021).

20. Odriozola-González, P., Planchuelo-Gómez, Á., Irurtia, M. J. \& de Luis-García, R. Psychological effects of the COVID-19 outbreak and lockdown among students and workers of a Spanish university. Psychiatry Res. 290, 113108 (2020).

21. Bourion-Bédès, S. et al. Psychological impact of the COVID-19 outbreak on students in a French region severely affected by the disease: Results of the PIMS-CoV 19 study. Psychiatry Res. 295, 113559 (2021).

22. Arsandaux, J. et al. Mental health condition of college students compared to non-students during COVID-19 lockdown: the CONFINS study. BMJ Open 11, e053231 (2021).

23. Ma, Z. et al. Mental health problems and correlates among 746,217 college students during the coronavirus disease 2019 outbreak in China. Epidemiol. Psychiatr. Sci. 29, e181 (2020).

24. Elmer, T., Mepham, K. \& Stadtfeld, C. Students under lockdown: Comparisons of students' social networks and mental health before and during the COVID-19 crisis in Switzerland. PLoS ONE 15, e0236337 (2020).

25. Lee, J., Solomon, M., Stead, T., Kwon, B. \& Ganti, L. Impact of COVID-19 on the mental health of US college students. BMC Psychol. 9, 95 (2021).

\section{Acknowledgements}

The i-Share and CONFINS team are currently supported by an unrestricted grant from the Nouvelle-Aquitaine Regional Council (Conseil Regional Nouvelle-Aquitaine) (Grant No 4370420) and by the Bordeaux 'Initiatives d'excellence' (IdEx) program of the University of Bordeaux (ANR-10-IDEX-03-02). M. Macalli was supported by a PhD grant of the Nouvelle-Aquitaine Regional Council (Grant No 17 EURE-0019) and by the PhD Digital Public Health Graduate School Program supported within the framework of the PIA3 (Investment for the Future) (Project Reference: 17-EURE-0019). This research was supported by the Agence Nationale de la recherche (ANR) (Project NANR-21-COVR-0029-01), the Direction Générale de l'Offre de Soins (DGOS), as part of a research program on "Suicide and its prevention 2020", organized by the Direction de la Recherche, des Études, de l'Évaluation et des Statistiques (DREES) as part of the work of the Observatoire National du Suicide (ONS) (Grant No 2103306249). This research is also supported by the European Union's Horizon 2020 research and innovation program (RESPOND). The RESPOND project is funded under Horizon 2020 - the Framework Programme for Research and Innovation (2014-2020). The content of this article reflects only the authors' views 
and the European Community is not liable for any use that may be made of the information contained therein. The authors are indebted to the i-Share operational team, Kappa Santé, and the Kap Code teams for their expert contributions and assistance.

\section{Author contributions}

M.M. and C.T. designed the study. M.M. conducted the statistical analysis. M.M., S.C. and C.T. wrote the first draft of the manuscript. All authors contributed to editing and commenting on the final version.

\section{Competing interests}

The authors declare no competing interests.

\section{Additional information}

Correspondence and requests for materials should be addressed to M.M. or C.T.

Reprints and permissions information is available at www.nature.com/reprints.

Publisher's note Springer Nature remains neutral with regard to jurisdictional claims in published maps and institutional affiliations.

(c) (i) Open Access This article is licensed under a Creative Commons Attribution 4.0 International License, which permits use, sharing, adaptation, distribution and reproduction in any medium or format, as long as you give appropriate credit to the original author(s) and the source, provide a link to the Creative Commons licence, and indicate if changes were made. The images or other third party material in this article are included in the article's Creative Commons licence, unless indicated otherwise in a credit line to the material. If material is not included in the article's Creative Commons licence and your intended use is not permitted by statutory regulation or exceeds the permitted use, you will need to obtain permission directly from the copyright holder. To view a copy of this licence, visit http://creativecommons.org/licenses/by/4.0/.

(C) The Author(s) 2021 